\title{
Evolutionary Perspectives on the Nature of Sibling Conflict: the Impact of Sex, Relatedness, and Co-residence
}

\author{
Catherine Salmon • Jessica Hehman
}

Published online: 27 March 2015

(C) Springer International Publishing 2015

\begin{abstract}
Our siblings can be our closest allies and yet are often our first rivals. What factors influence the nature of these relationships, and are there certain aspects that make our siblings more likely to be a source of conflict rather than solidarity? From an adaptationist perspective, sibling conflict should vary in frequency and intensity as a function of degree of relatedness. For example, conflict should be most frequent and intense between non-biological and step-siblings while conflict between full biological siblings should be least frequent and intense with half-sibling conflict being of an intermediate degree. This study examines levels of sibling conflict as a function of sex of participant, sex of sibling, degree of relatedness, and length of co-residence as well as self-reported sources of conflict. Results indicate that genetic relatedness does influence the frequency and intensity of conflict, though the most intense conflict was between non-biological siblings and the least was between half-siblings.
\end{abstract}

Keywords Kin selection · Sibling conflict · Inclusive fitness · Parental investment $\cdot$ Relatedness

Big sisters are the crab grass in the lawn of life.

Charles M. Schultz

For he today that sheds his blood with me shall be my brother.

William Shakespeare

C. Salmon $(\bowtie) \cdot J$. Hehman

Psychology Department, University of Redlands, Redlands, CA, USA

e-mail: catherine_salmon@redlands.edu

\section{Introduction}

Of all the relationships humans experience over their lifetimes, sibship can be the most long lasting and supportive and it can also be the most acrimonious and stressful. Our siblings are often there right from the start and, in many cases, are still there for the end, more so than parents who often die when their children are in the prime of life, own children who come on the scene later and may not stay around, or sexual partners who may come and go. Many writers have waxed poetic about the joys and trials of sibling relations and how they can be one's best friend or greatest competitor. Historical (and fictional) accounts often focus on the extremes of sibling behavior, from the Biblical account of Cain killing his brother Abel over perceived favoritism on the part of God (a form of parental favoritism) to ancient rulers who killed their siblings in order to guarantee their own children would inherit their resources and power. However, most sibling conflict is not siblicidal, though it can manifest in physical aggression. A number of researchers have suggested that sibling conflict is a normal part of human development (Cicirelli 1995) and that there are costs and benefits in terms of psychosocial and cognitive development (Campione-Barr and Smetana 2010; Dunn and Brown 1994). From an evolutionary perspective, what are the roots of sibling conflict? Specifically for this study, what factors influence how much sibling conflict occurs in any one family and why.

\section{Sibling Conflict Theory}

Sibling relationships can endure across the life span (Cicirelli 1995) and, as such, contain the potential for great solidarity as well as strife. Explaining altruistic motivations and behavior (even that directed at one's kin) from an evolutionary perspective presented a problem until Hamilton (1964) proposed kin 
selection theory. Hamilton redefined classic Darwinian fitness (i.e., survival and successful reproduction, hence the transmission of one's own genes into subsequent generations) into the concept of inclusive fitness, which encompasses not only one's own survival and reproduction but also that of genetically related individuals. According to "Hamilton's rule" (1964), the likelihood an individual will behave altruistically towards another depends on whether the degree of relatedness $(r)$ and the potential fitness benefit $(b)$ to the other person outweigh the potential fitness cost (c) to oneself (i.e., $r * b>$ $c)$. Thus, altruistic behavior directed towards kin serves as an indirect way to increase one's own inclusive fitness. Natural selection not only favors traits that increase individual survival and reproduction but also traits that increase the survival and reproduction of one's relatives. In addition, kin selection theory predicts that genetic relatedness should influence the likelihood of conflict and cooperation between individuals. Specifically, more cooperation (and less conflict) would be expected between genetically related individuals, with greater relatedness leading to greater cooperation (and even less conflict) when all other things are equal. These predictions are consistent with studies investigating feelings of subjective closeness and received support across adult relationships as a function of degree of relatedness with highest levels being directed to kin versus non-kin as well as greater levels being directed to more closely related kin, such as a sibling, versus more distantly related kin, such as a cousin (Neyer and Lang 2003)

Genetic relatedness and shared interests, however, do not mean identical interests. A clear example of this comes from parent-offspring conflict theory (Trivers 1974). Parents and offspring do not share identical genetic interests. Offspring will be selected to manipulate their parents in order to ensure higher investment, and parents will be selected to manipulate their offspring to suit their own (i.e., the parents) genetic interests. Whenever two parties have differing interests, there is a possibility of conflict. From an offspring's perspective, the more parental investment (e.g., resources such as time, energy, food, etc.), the better. From a parent's point of view, the more he/she invests in any one offspring, the less he/she can invest in other current or future offspring (Trivers 1972). According to parental investment theory, the amount and allocation of parental investment depend on the amount of resources available to parents, the quality of the offspring, and the potential for future offspring (Trivers 1972). Assuming availability of resources and equal quality of offspring, it would be expected that parents value each offspring equally and would encourage their children to value their siblings more than they might be naturally inclined to do. Each offspring, however, being more closely genetically related to itself than to any one sibling, values itself over its siblings. This brings about the possibility for sibling conflict as siblings compete for parental resources. Therefore, it could be expected that each sibling would try to receive more than their "fair share" of parental investment with the result being sibling conflict. Since the degree of relatedness also matters, one would expect greater levels of conflict (or less solidarity) between half-siblings who share only one parent relative to full siblings who share both (Holmes and Sherman 1982).

From an evolutionary perspective, conflict among siblings stems from rivalry over limited resources. Specifically, for human siblings, this means competition over limited parental resources. In modern societies, this would include attention, time, and money. In the ancestral past, this would have included limited food and basic resources such as shelter and time invested in teaching skills like hunting or tool making. As such, more conflict would be expected in families that have more limited parental resources as well as larger numbers of siblings. In relation to family size, evidence suggests more siblings are associated with more overall incidents of violence (Straus, Gelles, and Steinmetz 2006). Investigations of proximate explanations have found the most common sources of sibling conflict to involve issues of relative power, selfinterest such as the sharing of personal items, violation of rules (e.g., perceived immaturity and inappropriate behavior), and interests outside the family (McGuire, Manke, Eftekhari, and Dunn 2000). The most commonly cited source of conflict by both older and younger siblings is the sharing of personal possessions, and the least commonly cited source is competition over parental attention. This has been a consistent finding in studies conducted with toddlers and preschool-aged siblings (Dunn and Munn 1985; Steinmetz 1977), school-aged siblings (McGuire et al. 2000), as well as adolescent siblings who noted conflict over personal space and possessions as not only the most frequent source of conflict but also the most intense (Campione-Barr and Smetana 2010).

\section{What Factors May Influence Whether a Sibling is Seen as a Resource Versus a Rival?}

Sex of Sibling Previous research suggests that sex influences sibling-focused behavior. Boys have been found to have more conflict with their siblings than do girls (Brody, Stoneman, MacKinnon, and MacKinnon 1985). In addition, evidence suggests that boys are more violent towards their siblings than are girls, with the highest level of sibling violence occurring between brothers (Straus et al. 2006). It has also been demonstrated that opposite-sex siblings have more conflict than do same-sex siblings (Dunn and Kendrick 1982; Campione-Barr and Smetana 2010). Older sisters often serve as caretakers to young siblings (Bove et al., 2002), and several studies suggest that sister-sister relationships are typically closer than brother-sister ones (Pollet 2007; White and Riedman 1992a), which also fits with studies that suggest a more kin-oriented role for women in general (Hrdy 2005; Salmon and Daly 
1996, 1998). It is also the case, however, that same-sex individuals are theoretically in more direct conflict as they are more likely to be in competition over the same resources whereas opposite-sex siblings are less likely to be competing over the same resources. While all siblings may be equal food competitors, for example, they are not competing for the same mates. Given the evidence that sex plays a role in the levels of sibling conflict, in the current study, we controlled for sex of the respondent and sex of sibling in investigating the larger question regarding the effect of relatedness on levels of sibling conflict.

Relatedness We have already mentioned the theoretical relevance of relatedness to the question of sibling conflict; surprisingly, the effect of relatedness on levels of conflict has been understudied in human research on sibling relations. Emlen (1997) suggested that individuals will invest more in full siblings than in half-siblings or step-siblings with the assumption that sibling ties are weaker with decreasing degrees of relatedness and conflict will be greater. There have been several studies looking at the solidarity side of sibship with data that generally support Emlen's prediction including Jankowiak and Diderich's (2000) study of Mormons showing a clear preference for full siblings over half-siblings despite the ideological pressure to treat them the same. In a sample of Dutch adults, Pollet (2007) found that relatedness predicted interaction patterns between siblings while White and Riedmann (1992b) demonstrated more contact between full siblings than between step/half-siblings. Similarly, twin studies have found higher levels of cooperation and closer relationships between monozygotic twins than between dizygotic twins (Segal 2005). To our knowledge, however, there has not been a direct test of the effect of degree of relatedness on the actual levels of sibling conflict. The closest investigation of such a relationship was conducted by Michalski and colleagues (2007) who found a negative relationship (though not statistically significant) between the likelihood of siblicide and genetic relatedness in a historical Chicago sample. This study, however, did not actually address the effect of relatedness of siblings as it compared rates of siblicide between full siblings and sibling-in-law (i.e., no genetic relatedness at all, but rather affinal kin). Therefore, the current study represents the first test of the effect of relatedness between siblings on the level of sibling conflict.

Birth Spacing and Length of Co-residence Other factors that seem likely to play a role in the levels of sibling conflict are birth spacing and length of co-residence. Previous studies have indicated greater levels of conflict between siblings who are closer in age, with the greatest conflict occurring between siblings who are within 2 years of age and who would presumably be competing for similar parental resources (Cicirelli
1995). Greater birth spacing has been linked to less conflict between siblings during childhood as well as less close relationships in adulthood (Pollet 2007). Although no studies have been conducted investigating the role of length of co-residence on levels of sibling conflict, it could be the case that longer duration of coresidence contributes to a greater sense of sibship and solidarity (i.e., therefore less conflict) between siblings. Therefore, in the current study, we controlled for the absolute age difference between siblings as well as length of co-residence in investigating the role of degree of relatedness on levels of sibling conflict.

\section{Current Study}

This study examined frequency and intensity of conflict between siblings with the following predictions:

Prediction 1: Sex of sibling influences the level of conflict with greater conflict expected between samesex siblings relative to opposite-sex siblings.

Prediction 2: Degree of relatedness influences the degree of conflict with greater levels of conflict expected between unrelated siblings than half-siblings and greater conflict between half-siblings than full siblings.

Prediction 3: Duration of co-residence influences the level of conflict with reduced levels of conflict expected between siblings who have co-resided longer.

\section{Method}

Participants

Participants included 345 young adults (106 males and 239 females) between the ages of 18 and $22(M=18.6, \mathrm{SD}=.94)$ who reported on 530 siblings. Out of the 530 siblings, 268 were same-sex sibling pairs and 262 were opposite-sex sibling pairs. There were 451 full siblings, 52 half-siblings, and 27 non-biological siblings (i.e., adopted/step-siblings). Participants were recruited from introductory psychology courses and received course credit for their participation in the study. We have co-residence data for a subset of participants $(n=139,40$ males, 99 females; mean age $=18.6$, $\mathrm{SD}=.85$ ), reporting on 206 siblings (94 same-sex siblings, 112 opposite-sex siblings; 163 full, 34 half, and 9 nonbiological siblings). 


\section{Measures}

Demographic Questions Participants were asked to selfreport their sex, age, number of siblings, and the birth order of themselves and their siblings.

Sibling Issues Checklist The sibling issue checklist is comprised of a list of 20 potential sibling conflict issues for which participants are asked to rate: (i) how frequently the issues arose between themselves and a particular sibling on a 5point Likert scale ranging from 1 (never) to 5 (very often) and (ii) how intense those issues were on a 5-point Likert scale ranging from 1 (calm) to 5 (very angry) (Campione-Barr and Smetana 2010). The scale yields overall frequency and intensity of conflict scores as well as two factor scores (i.e., conflict over equality and fairness and conflict over invasion of personal and psychological space). Conflict over equality and fairness includes items such as conflict over "parents' attention" and "whose turn to do chores." Conflict over invasion of personal and psychological space includes items such as "telling other what to do" and "borrowing things without permission." The overall conflict scores range from 20 to 100 , with higher scores indicating more frequent and more intense conflict. The factor scores range from 10 to 50, with higher scores indicating more frequent and more intense conflict of that particular type. Participants were asked to complete the sibling issue checklist for each of their siblings, indicating that sibling's sex, age, and degree of relatedness (full sibling, halfsibling, step-sibling, or adopted sibling).

Co-residence A subset of the sample (as described above) was asked to report how long they co-resided with each of their siblings ("I lived with this sibling from the time I was (age) until I was (age)"). This data was used to calculate the duration of co-residence for each participant with each of their siblings.

\section{Procedure}

Participants were sent a link to complete the survey online via SurveyMonkey. Participants first responded to the demographic questions, followed by the sibling issue checklist for each sibling, which included the co-residence question for a subset of the sample. After completion of the survey, participants were given course credit for their time.

\section{Results}

The means (and standard deviations) of intensity of overall conflict as a function of the main effects of degree of relatedness and sex of sibling (same sex vs. opposite sex) appear in Table 1. Separate analyses were done on the two factor scores,
Table 1 Mean intensity of overall conflict as a function of the main effects of degree of relatedness and sex of sibling

\begin{tabular}{llll}
\hline & Number & M & SD \\
\hline Relatedness & & & \\
$\quad$ Full & 451 & $30.3 \mathrm{a}$ & 14.6 \\
Half & 52 & $19.6 \mathrm{a}, \mathrm{b}$ & 14.0 \\
$\quad$ Non-biological & 27 & $33.1 \mathrm{~b}$ & 17.7 \\
Sex of sibling & & & \\
$\quad$ Same sex & 268 & $30.8 \mathrm{c}$ & 15.1 \\
$\quad$ Opposite sex & 262 & $27.9 \mathrm{c}$ & 14.9 \\
\hline
\end{tabular}

Means followed by common lowercase letters are significantly different at less than the .05 level of confidence

and the results were not significantly different than the overall score analyses, so only the overall score analyses are reported here. Inspection of Table 1 indicates that (1) respondents reported more intense conflict with their same-sex siblings versus their opposite-sex siblings and (2) respondents reported more intense conflict with their full and non-biological siblings relative to their half-siblings.

A hierarchical regression analysis was conducted to test the first two predictions: (1) that there would be greater conflict between same-sex siblings relative to opposite-sex siblings and (2) that there would be greater conflict between unrelated siblings than half-siblings and greater conflict between halfsiblings than full siblings. In order to control for the demographic variables before accounting for the effect of degree of relatedness on the intensity of overall conflict between siblings, sex of respondent (coded as $0=$ female, $1=$ male) was entered in step 1, age difference (absolute age difference between respondent and sibling) was entered in step 2, sex of sibling (coded as $0=$ same sex, $1=$ opposite sex) was entered in step 3, and degree of relatedness was entered in step 4 . Degree of relatedness was added into the model using two dummy variables: full sibling (coded as $1=$ full sibling, $0=$ other) and half-sibling (coded as $1=$ half-sibling, $0=$ other). Results from this analysis are summarized in Table 2.

On step 1, the respondent's sex did not account for any significant amount of the variance in intensity of overall conflict $(F(1528)=0.13, p=.72)$. On step 2 , the absolute age difference between respondent and sibling accounted for an additional $4.1 \%$ of the variance in intensity of overall conflict $(F(1527)=22.50, p<.001)$. Inspection of the standardized regression coefficient $(\beta)$ indicates that respondents experienced significantly more intense conflict with siblings who were closer in age to themselves. On step 3, sex of the sibling accounted for an additional $1 \%$ of the variance in intensity of overall conflict $(F(1526)=4.92, p=.03)$. Consistent with the first prediction, inspection of the standardized regression coefficient $(\beta)$ indicated that respondents experienced significantly more intense conflict with their same-sex siblings 
Table 2 Hierarchical regression analysis predicting intensity of overall conflict as a function of respondent sex, age difference, sex of sibling, and degree of relatedness

\begin{tabular}{|c|c|c|c|c|c|}
\hline Step & Variable & $B$ & $\operatorname{SE}(B)$ & $\beta$ & $\Delta R^{2}$ \\
\hline \multirow[t]{2}{*}{ Step 1} & & & & & .00 \\
\hline & Sex of respondent $\mathrm{t}^{\mathrm{a}}$ & .53 & 1.46 & .02 & \\
\hline \multirow[t]{2}{*}{ Step 2} & & & & & $.04 * * *$ \\
\hline & Age difference ${ }^{b}$ & -.89 & .19 & $-.20 * * *$ & \\
\hline \multirow[t]{2}{*}{ Step 3} & & & & & $.01 *$ \\
\hline & Sex of sibling ${ }^{c}$ & -2.38 & & 1.28 & $-.09 *$ \\
\hline \multirow[t]{4}{*}{ Step 4} & & & & & $.02 * *$ \\
\hline & Relatedness $^{\mathrm{d}}$ & & & & \\
\hline & Full & -2.52 & 2.90 & -.06 & \\
\hline & Half & -10.44 & 3.57 & $-.21 * *$ & \\
\hline
\end{tabular}

$n=545$

${ }^{\text {a }}$ Coded $0=$ female, $1=$ male

${ }^{\mathrm{b}}$ Calculated as absolute difference between respondent's and sibling's age

${ }^{\mathrm{c}}$ Coded $0=$ same sex, $1=$ opposite sex

${ }^{\mathrm{d}}$ Degree of relatedness represented as two dummy variables: Full sibling ( $1=$ full sibling, $0=$ other $)$ and half-sibling $(1=$ half-sibling, $0=$ other $)$

${ }^{*} p<.05 ; * * p<.01 ; * * * p<.001$

relative to their opposite sex siblings. Finally, on step 4, degree of relatedness accounted for an additional $2.3 \%$ of the variance in intensity of overall conflict $(F(2524)=6.53, p=.002)$. Inconsistent with the second prediction that respondents would experience the greatest amount of conflict with their non-biological siblings followed by lesser conflict with their half-siblings and the least amount of conflict with their full siblings, inspection of the standardized regression coefficients $(\beta \mathrm{s})$ indicates that respondents experienced significantly less intense conflict with their half-siblings relative to their full and non-biological siblings. Overall, the main effects of the four factors accounted for approximately $7.3 \%$ of the variance in intensity of overall conflict $(F(5524)=8.72, p<.001)$.

A follow-up hierarchical regression analysis was conducted using a subset of the sample for which we had co-residence data to test the third prediction that siblings who have coresided longer would experience reduced levels of conflict. In order to control for the effect of duration of co-residence and the other demographic variables before testing for the effect of degree of relatedness, length of co-residence was entered in step 1, sex of respondent was entered in step 2, absolute age difference between the respondent and sibling was entered in step 3, sex of sibling was entered in step 4, and degree of relatedness was entered in step 5. Results from this analysis are summarized in Table 3.

On step 1, length of co-residence accounted for about $9 \%$ of the variance in intensity of overall conflict $(F(1204)=$ $20.96, p<.001)$. Inconsistent with the prediction that longer
Table 3 Hierarchical regression analysis predicting intensity of overall conflict as a function of length of co-residence, respondent sex, age difference, sex of sibling, and degree of relatedness

\begin{tabular}{|c|c|c|c|c|c|}
\hline Step & Variable & $B$ & $\mathrm{SE}(B)$ & $\beta$ & $\Delta R^{2}$ \\
\hline \multirow[t]{2}{*}{ Step 1} & & & & & $.09 * * *$ \\
\hline & Co-residence & 1.13 & .25 & $.31 * * *$ & \\
\hline \multirow[t]{2}{*}{ Step 2} & & & & & .00 \\
\hline & Sex of respondent ${ }^{\mathrm{a}}$ & -.26 & 2.36 & -.01 & \\
\hline \multirow[t]{2}{*}{ Step 3} & & & & & $.03 *$ \\
\hline & Age difference ${ }^{b}$ & -1.10 & .44 & $-.24 *$ & \\
\hline \multirow[t]{2}{*}{ Step 4} & & & & & .01 \\
\hline & Sex of sibling ${ }^{c}$ & -2.81 & & 2.01 & -.09 \\
\hline \multirow[t]{4}{*}{ Step 5} & & & & & $.04 *$ \\
\hline & Relatedness $^{\mathrm{d}}$ & & & & \\
\hline & Full & -9.18 & 5.17 & -.25 & \\
\hline & Half & -15.45 & 5.65 & $-.38 * *$ & \\
\hline
\end{tabular}

$n=206$

${ }^{\mathrm{a}}$ Coded $0=$ female, 1 = male

${ }^{\mathrm{b}}$ Calculated as absolute difference between respondent's and sibling's age

${ }^{\mathrm{c}}$ Coded $0=$ same sex, $1=$ opposite sex

${ }^{\mathrm{d}}$ Degree of relatedness represented as two dummy variables: Full sibling ( $1=$ full sibling, $0=$ other $)$ and half-sibling $(1=$ half-sibling, $0=$ other $)$

${ }^{*} p<.05 ; * * p<.01 ; * * *<.001$

co-residence would be associated with reduced conflict, inspection of the $\beta$ indicates that longer co-residence is associated with more intense sibling conflict. On step 2, sex of the respondent did not significantly account for any additional variance in intensity of overall conflict with duration of coresidence already added into the model $(F(1203)=.01$, $p=.91)$. On step 3, the absolute age difference between respondent and sibling accounted for an additional $3 \%$ of the variance in intensity of overall conflict $(F(1202)=6.24$, $p=.01)$. Inspection of the $\beta$ indicates that as the age difference between siblings increases, intensity of sibling conflict decreases. On step 4, sex of sibling did not significantly account for any additional variance in intensity of overall conflict $(F$ $(1201)=1.95, p=.16)$. Finally, on step 5, degree of relatedness accounted for an additional $4 \%$ of the variance in intensity of overall conflict $(F(2199)=4.15, p=.02)$. Inspection of the $\beta \mathrm{s}$ indicates that respondents experienced significantly less intense conflict with their half-siblings relative to their full and non-biological siblings. Overall, the main effects of the five factors accounted for approximately $16.4 \%$ of the variance in intensity of overall conflict $(F(6199)=6.49, p<.001)$.

To further investigate the effect of length of co-residence on the intensity of sibling conflict between full, half, and nonbiological siblings, post hoc comparisons were made to test for differences in intensity of conflict as a function of degree of relatedness (controlling for duration of co-residence). As 
can be seen in Fig. 1, the post hoc comparisons revealed that respondents experienced the greatest intensity of conflict with non-biological siblings, followed by their full siblings, and the least amount of conflict with their half-siblings.

\section{Discussion}

The results clearly demonstrate more intense conflict between same-sex siblings as predicted based on the notion that they are more likely in competition for the same resources and in line with studies that have documented greater violence between brothers (Straus et al. 2006). In this study as well, brothers did have more intense, sometimes physical, conflict than sisters or brother-sister pairs. In addition, higher levels of conflict were seen between non-biological siblings and full siblings than between half-siblings, not what we had originally predicted (which was that non-biological siblings would have the most conflict, followed by half-siblings, and then full siblings with the least conflict). With regard to our prediction that increasing co-residence duration would be related to less conflict, we found the opposite, that increasing co-residence was associated with greater intensity of conflict. In addition, greater birth spacing was associated with less intensity of conflict which was expected based on parental investment theory. Close birth spacing increases competition for the same parental resources as siblings close in age will have similar needs (Sulloway 1996).

Based on inclusive fitness (Hamilton 1964) and studies demonstrating greater solidarity between full siblings than half-siblings (Jankowiak and Diderich 2000; Pollet 2007), we expected to see greater conflict as the degree of relatedness decreased from full to half to adopted/step siblings. While the greatest intensity of conflict was reported between nonbiological siblings, the intensity of conflict was greater between full siblings than half-siblings. This raises several questions. It may be that different mechanisms underlie sibling conflict and solidarity such that relatedness does not have a decreasing impact on conflict in the way it has an increasing impact on solidarity, at least not when it comes to conflict between full versus half-siblings. It is also possible that individuals have different expectations for full versus half-sibling relationships, and what might be perceived and remarked on as conflict between full siblings is considered differently with half-siblings. It may also be that in human families, especially for children that may have already experienced divorce, siblings in mixed relatedness families may work especially hard to maintain good sibling relationships so as not to pose any risks to the integrity of the family. These possible explanations should be explored in future work.

Individuals in traditional societies interact more with closely related kin than with those more distantly connected (Hames 1979, 1987). Pollet (2007) has suggested that halfsiblings interact less than full siblings, creating fewer opportunities to build solidarity or conflict. Our results with regard to co-residence suggest that this may be one factor at play in sibling conflict, in that longer (rather than shorter) coresidence was associated with greater conflict among our siblings. The longer they lived together, the more frequent and intense their conflict. One reason full siblings have high levels of conflict may be that they are simply exposed to conflictproducing situations with each other more often than halfsiblings. They are also exposed to more opportunities to cooperate and form solidary bonds. Thus, we would expect longer co-residence to be associated with increased conflict and increased sociality.

One limitation of this study is that we only had selfreported intensity and frequency of conflict from one member of each sibship. It is possible that, for example, a sibling living in the maternal home with a younger half-sibling would
Fig. 1 Mean intensity of sibling conflict (controlling for length of co-residence) as a function of degree of relatedness




perceive the level of conflict between them differently than the younger sibling. It would also be helpful to have a larger number of step and/or adopted participants. This subgroup was the smallest in our sample, and as a result, we could not analyze the step or adopted sibling groups separately. In the future, it would also be useful to compare sibling conflict and cooperation in the same study so as to further clarify the mechanisms behind these two aspects to sibling interactions. In addition, we would also encourage the testing of these hypotheses about sibling conflict in other, non-western, populations.

\section{Conclusion}

In summary, we found that genetic relatedness influenced the frequency and intensity of sibling conflict. However, contrary to our prediction, the most intense conflict was with nonbiological siblings and the least was with half-siblings with full siblings in between. In addition, duration of co-residency and birth interval also influenced the level of conflict with less co-residency and longer birth intervals being associated with less conflict.

Acknowledgments We would like to thank the hosts and those who attended The Evolution of Violence conference at Oakland University for inspiring us to look at this aspect of familial violence as well as William Jankowiak and two anonymous reviewers for their feedback.

\section{References}

Bove, R. M., Valeggia, C., \& Ellison, P. T. (2002). Girl helpers and nursing women's activities among the Toba of Argentina. Human Nature, 13, 457-472.

Brody, G. H., Stoneman, Z., MacKinnon, C. E., \& MacKinnon, R. (1985). Role relationships and behaviors between preschool-aged and school-age sibling pairs. Developmental Psychology, 21, 124 129.

Campione-Barr, N., \& Smetana, J. G. (2010). "Who said you could wear my sweater?" Adolescent siblings' conflicts and association with relationship quality. Child Development, 81(2), 464-471.

Cicirelli, V. G. (1995). Sibling relationships across the life span. New York: Plenum Press.

Dunn, J., \& Brown, J. (1994). Affect expression in the family, children's understanding of emotions, and their interactions with others. Merrill-Palmer Quarterly, 40, 120-137.

Dunn, J., \& Kendrick, C. (1982). Siblings: love, envy, and understanding. Cambridge: Cambridge University Press.

Dunn, J., \& Munn, P. (1985). Becoming a family member: family conflict and the development of social understanding in the second year. Child Development, 56, 764-774.
Emlen, S. T. (1997). The evolutionary study of human family systems. Social Science Information, 34, 563-589.

Hamilton, W. D. (1964). The genetic evolution of social behavior, I and II. Journal of Theoretical Biology, 7, 1-52.

Hames, R. D. (1979). Relatedness and interaction among the Ye'kwana: a preliminary analysis. In N. Chagnon \& W. Irons (Eds.), Evolutionary biology and human behavior (pp. 238-249). Cambridge: Duxbury Press.

Hames, R. D. (1987). Relatedness and garden labor exchange among the Ye'kwana. Ethology and Sociobiology, 8, 259-284.

Holmes, W. G., \& Sherman, P. W. (1982). The ontogeny of kin recognition in two species of ground squirrels. American Zoologist, 22, 491-517.

Hrdy, S. B. (2005). Evolutionary context of human development: the cooperative breeding model. In S. C. Carter, L. Ahnert, K. Grossman, S. B. Hrdy, M. E. Lamb, S. W. Porges, \& N. Sachser (Eds.), Attachment and bonding: a new synthesis (pp. 9-32). Cambridge: MIT Press.

Jankowiak, W., \& Diderich, M. (2000). Sibling solidarity in a polygamous community in the USA: unpacking inclusive fitness. Evolution and Human Behavior, 21, 125-139.

McGuire, S., Manke, B., Eftekhari, A., \& Dunn, J. (2000). Children's perceptions of sibling conflict during middle childhood: issues and sibling (dis)similarity. Social Development, 9(2), 173-190.

Michalski, R. L., Russell, D. P., Shackelford, T. K., \& WeekesShackelford, V. A. (2007). Siblicide and genetic relatedness in Chicago, 1870-1930. Homicide Studies, 11, 231-237.

Neyer, F. J., \& Lang, F. R. (2003). Blood is thicker than water: kinship orientation across adulthood. Journal of Personality and Social Psychology, 84, 310-321.

Pollet, T. V. (2007). Genetic relatedness and sibling relationship characteristics in a modern society. Evolution and Human Behavior, 28, 176-185.

Salmon, C. A., \& Daly, M. (1996). On the importance of kin relations to Canadian women and men. Ethology \& Sociobiology 17: 289-297.

Salmon, C. A., \& Daly, M. (1998). Birth order and familial sentiment: middleborns are different. Evolution and Human Behavior, 19, 299 312.

Segal, N. L. (2005). Evolutionary studies of cooperation, competition, and altruism: a twin-based approach. In R. L. Burgess \& K. B. MacDonald (Eds.), Evolutionary perspectives on human development (2nd ed., pp. 265-304). Thousand Oaks: Sage.

Steinmetz, S. K. (1977). The use of force for resolving family conflict: the training ground for abuse. The Family Coordinator, 26, 19-26.

Straus, M., Gelles, R. J., \& Steinmetz, S. K. (2006). Behind closed doors: violence in the American family. Piscataway: Transaction Publishers.

Sulloway, F. J. (1996). Born to rebel: birth order, family dynamics, and creative lives. New York: Pantheon.

Trivers, R. L. (1972). Parental investment and sexual selection. In B. Campbell (Ed.), Sexual section and the descent of man (pp. 136179). Chicago: Aldine Publishing Company.

Trivers, R. L. (1974). Parent-offspring conflict. American Zoologist, 14, 249-264.

White, L. K., \& Riedmann, A. (1992a). Ties among adult siblings. Social Forces, 71, 85-102.

White, L. K., \& Riedmann, A. (1992b). When the Brady bunch grows up: step/half- and full sibling relationships in adulthood. Journal of Marriage and the Family, 54, 197-208. 